\title{
Analytical and Sensory Assessment of Hoppy Aroma and Bitterness of Conventionally Hopped and Advanced Hopped Pilsner Beers
}

\author{
Filip Van Opstaele*, Gert De Rouck, Jessika De Clippeleer, Guido Aerts \\ and Luc De Cooman
}

\begin{abstract}
J. Inst. Brew. 116(4), 445-458, 2010

Analytical and sensory aspects of hoppy aroma of conventionally hopped and advanced hopped pilot Pilsner beers were investigated. Linalool and several sesquiterpenoids were used as analytical markers for the hoppy aroma of the beers. Levels of linalool and sesquiterpenoids in the fresh beers, as well as sensory characteristics of hoppy aroma (intensity and attributed aroma descriptor(s)) clearly depended on the applied hop aromatisation technology and on the type of hop oil fraction used in advanced hopping. The most pronounced hoppy aroma was observed for the advanced bittered beers, either aromatised postfermentation using a polar hop essence or at the end of wort boiling using pellets (late-hopping). However, all refined hop oil fractions used in this study for advanced aromatisation clearly affected the hoppy aroma impression. Analytical data on staling indicators, combined with sensory evaluations, further suggest that hop oil preparations may also affect flavour stability of the resulting beers in a positive way. In general, it can be concluded that hop aromatisation, whether performed in the advanced or conventional way, appears to mask beer staling, as demonstrated by lower overall sensory ageing scores.
\end{abstract}

Key words: advanced hopping, flavour stability, hop essences, hop oil, hoppy aroma.

\section{INTRODUCTION}

A pleasant beer flavour is the result of a fine and subtle balance between numerous volatile and non-volatile chemical compounds originating or derived from the brewing raw materials. A key role for beer flavour and consumers' appreciation of the final product is attributed to the use of hops. Indeed, although hops or hop products

KaHo St.-Lieven, Association K.U. Leuven, Department of Microbial and Molecular Systems (M2S), Leuven Food Science and Nutrition Research Centre (LFoRCe), Laboratory of Enzyme, Fermentation and Brewing Technology, Technology Campus, Gebroeders Desmetstraat 1, B-9000 Gent, Belgium.

${ }^{*}$ Corresponding author. E-mail: filip.vanopstaele @ kahosl.be Parts of this paper were presented at the 2nd International Symposium for Young Scientists and Technologists in Malting, Brewing and Distilling, May 19-21, 2010 in Freising - Weihenstephan, Germany.

Publication no. G-2011-0113-105

(c) 2010 The Institute of Brewing \& Distilling are only a minor ingredient when compared to brewing water or malt, they have a determining impact on the organoleptic properties of beer.

The use of hops in brewing practice affects beer flavour in various ways. In particular, beer bitterness and hoppy aroma are derived from hops, due to the presence of $\alpha$-acids and hop essential oil in the lupulin glands. The $\alpha$-acids act as precursors for the real bittering principles (i.e., iso- $\alpha$-acids), while hoppy aroma is caused by volatiles in the beer matrix that are originally present in or are derived from hop essential oils. Furthermore, hop polyphenols may also contribute positively to beer flavour quality by enhancing mouthfeel and even stability of the flavour upon storage ${ }^{12}$.

Nowadays, the chemistry behind hop- $\alpha$-acids derived beer bitterness is well understood, and as a consequence beer bittering is controllable in brewing practice. This definitely holds true when applying advanced bittering preparations such as (reduced) isomerised extracts containing iso- $\alpha$-acids, dihydroiso- $\alpha$-acids or tetrahydroiso$\alpha$-acids ${ }^{6}$. When combined with appropriate analytical techniques (e.g., HPLC) for quantitative and qualitative evaluation of these advanced products and adequate dosing technologies, the brewer is currently able to prepare beers with a reproducible bitterness and an improved bitterness stability on storage ${ }^{4}$.

However, in contrast to beer bitterness, hoppy aroma is, even at present, far from fully understood. Indeed, although it is generally accepted that hoppy aroma is derived from hop essential oils, flavour-active key compounds causing this highly desirable aspect of beer aroma remain to be identified. This gap can be ascribed to the extreme chemical complexity and varietal dependency of hop essential oil itself, and to modifications and losses of hop oil constituents that take place along the brewing process. Consequently, inconsistent hop aromas represent a serious quality problem in view of a reproducible and sufficiently stable beer flavour.

In particular, the traditional practices of kettle hopping, late- and dry-hopping with hop cones or hop pellets, inherently lead to flavour inconsistency. Therefore, different types of hop products are nowadays available for improved control of hoppy character and diversification of the beer flavour during the development of new beers ${ }^{1}$. In respect to hoppy aroma, hop oil preparations are commercially available to impart late- or dry-hop flavour or to 
introduce citrusy, floral, fruity, sylvan, spicy or herbal flavour top-notes into the beer ${ }^{29,34}$. Advanced aromatisation clearly offers opportunities in view of high utilisation of hop oil constituents and increased reproducibility of hoppy aroma impressions. Indeed, hop oil preparations can be dosed in precise amounts at the final stage of beer production, thereby reducing the risk for further losses or modifications of important hop aroma constituents 5 .

Although the aspect of hoppy aroma has not been completely unravelled since flavour-active compounds remain to be identified, several analytical markers for hop aroma (referring to hops) and hoppy aroma (referring to beer) have been proposed ${ }^{31}$. For instance, the monoterpene linalool has been proposed as an excellent marker for both the intensity and the quality of hoppy aroma of finished beer $^{21,22}$ and it has proven to be highly effective for evaluating various hopping technologies and their impact on final hoppy aroma ${ }^{22,23}$. Moreover, it was found by Fritsch and Schieberle ${ }^{9}$ that linalool is a determining odorant in Bavarian Pilsner-type beers. On the other hand, the sesquiterpenoid fraction of hops has been related to the socalled 'spicy' or 'noble' aspect of hoppy aroma ${ }^{8,10,11,16,27,33,40}$, although to date this view remains somewhat controversial in the literature ${ }^{16,24}$.

This study was aimed at the analytical and sensory evaluation of hoppy aroma of both conventionally and advanced hopped Pilsner type beers. The major objective was to evaluate the use of several innovative hop oil preparations $^{5,37}$ in brewing practice, and to compare the resulting flavour profiles of the advanced hopped beers with those of traditionally hopped lagers. Hoppy aroma of the fresh beers was evaluated by both sensory and analytical protocols, including analytical determination of linalool and several markers of the sesquiterpenoid fraction of hop oil. Furthermore, since only limited information on the stability of hoppy aroma during beer ageing is currently available ${ }^{20,21,32}$, and because it has been reported that hops and hop products may affect flavour stability $^{26,36,39,41}$, beer ageing experiments were performed. Besides investigation of the stability of hoppy aroma as such on forced ageing, the potential effect of the hop products, in particular the fractionated hop oils, on the overall flavour stability of the pilot beers was assessed by analytical determination of staling indicators (i.e., marker aldehydes and bittering principles) and sensory ageing scores.

\section{MATERIALS AND METHODS}

\section{Preparation of total hop essential oil and hop essences}

For advanced aromatisation of pilot beers, innovative hop oil preparations were used. These novel products were prepared according to our own hop aroma extraction methodology, which is based on direct supercritical fluid extraction (SFE) of hop pellets with carbon dioxide. Selective and fractionated extraction of hop oils was obtained by $\mathrm{CO}_{2}$ density programming and subsequent separation by column chromatography as described previously $^{37}$. All hop oil preparations were extracted from pellets T90 cv. Spalter Select. Hop pellets (5-6 g) were disrupted using a pestle and mortar, brought into stainless steel extraction cells and then extracted with carbon dioxide (SFE/SFC grade, Air Liquide, Liège, Belgium) in the supercritical state, using a Dionex SFE-703 supercritical fluid extractor (Dionex, Sunnyvale, California, USA).

For extraction of total hop essential oil, pellets were extracted by applying a pressure of 110 atm in combination with a temperature of $50^{\circ} \mathrm{C}$.

The 'polar essence' was prepared from total hop essential oil by further fractionation via solid phase extraction (SPE). For that purpose, SPE cartridges (Varian Bond Elut C18, $500 \mathrm{mg}$, Varian, USA) were pre-conditioned with 10 $\mathrm{mL}$ of HPLC-grade ethanol and then $10 \mathrm{~mL}$ of ethanol/water $(1 / 1 ; \mathrm{v} / \mathrm{v})$. SFE total hop oil was brought on top of the SPE-column and separated into 6 fractions $(3 \mathrm{~mL}$ each) by gradually increasing the ethanol concentration from $50 \%$ to $100 \%$. The ethanol/water fraction comprising $70 \%$ ethanol represents the 'polar hop essence' (enriched in the oxygenated fraction of total hop oil).

Hop oil essences with typical floral or spicy flavour attributes were obtained via a two-step extraction methodology. Floral hop extracts were prepared via SFE at 90 atm and $50^{\circ} \mathrm{C}$ and further fractionated by SPE as described above. The ethanol/water fraction comprising $70 \%$ ethanol represents the 'floral essence' which is enriched in the most volatile fraction of hop essential oil.

Spicy hop extract was prepared by further SFE at 110 atm and $50^{\circ} \mathrm{C}$ of the hop residue remaining from preparation of the floral extract. Further fractionation of the spicy extract by SPE (see above) resulted in the 'spicy essence' (70\% ethanol fraction, enriched in the oxygenated sesquiterpenoid fraction of hop essential oil).

\section{Preparation of pilot beers}

All pilot beers were prepared in our pilot brewery on a $5 \mathrm{hL}$ scale. This brewing installation is a prototype for innovative wort production as described by De Rouck et al. ${ }^{7}$ For this comparative study three similar basic brews, differing only in the hopping regime, were prepared using the following conditions: $84 \mathrm{~kg}$ fine milled Pilsner malt (wet disc mill, Meura) was mixed with $1.85 \mathrm{hL}$ reverse osmosis brewing water with the addition of $\mathrm{CaCl}_{2}(80$ ppm $\left.\mathrm{Ca}^{2+}\right)$ and $120 \mathrm{~mL}$ lactic acid $(30 \%$, v/v); mashing-in:

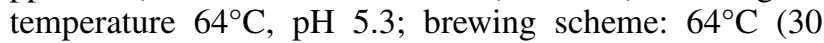
$\mathrm{min}), 72^{\circ} \mathrm{C}(20 \mathrm{~min}), 78^{\circ} \mathrm{C}(1 \mathrm{~min})$ (temperature increase: $\left.1^{\circ} \mathrm{C} / \mathrm{min}\right)$; wort filtration: membrane assisted thin bed filter; wort boiling: $60 \mathrm{~min}$ atmospheric boiling (evaporation about 5\%); at the end of boiling, $0.2 \mathrm{ppm} \mathrm{Zn}^{2+}$ ions were added; wort clarification: open whirlpool; after cooling and aeration, the wort (original gravity: $12^{\circ} \mathrm{P}$ ) was pitched with $10^{7}$ yeast cells/mL (inoculum: dry yeast, strain W 34/70 (Fermentis), was hydrated for $1 \mathrm{~h}$ in sterile water with a volume of 10 times the weight of the dry yeast); primary fermentation: 8 days at $12^{\circ} \mathrm{C}$ in cylindroconical tanks; maturation: 10 days at $-0.5^{\circ} \mathrm{C}$; beer filtration: kieselguhr/cellulose sheets (pore size $1 \mu \mathrm{m}$ ); $\mathrm{CO}_{2}$ saturation up to $5.6 \mathrm{~g} / \mathrm{L}$; packaging: 6 head rotating counter pressure filler (monobloc, CIMEC, Italy) using double pre-evacuation with intermediate $\mathrm{CO}_{2}$ rinsing and overfoaming with hot water injection before capping (final oxygen levels: below $50 \mathrm{ppb}$ ). 
Detailed information on the hopping of the three basic brews is presented below and in Table I.

Brew 1: conventional bittering (code: 'Con'). After mash-filtration, the wort was divided into 2 equal volumes of $2 \mathrm{hL}$ and dispersed into two different kettles for boiling. Hop addition was performed at the start of boil aiming at a final beer bitterness of $25 \mathrm{ppm}$ iso- $\alpha$-acids. Hopping was performed by adding $148.7 \mathrm{~g}$ of hop pellets $\mathrm{cv}$. Magnum ( $\alpha$-acids: $10.5 \%(\mathrm{w} / \mathrm{w})$, presumed utilisation: $32 \%$, code: 'Con-pel') or 35.0 g carbon dioxide extract $(\alpha$-acids: $43.4 \%(\mathrm{w} / \mathrm{w})$, presumed utilisation: $33 \%$, code: 'Con- $\left.\mathrm{CO}_{2}{ }^{\prime}\right)$, respectively.

Brew 2: advanced bittering (code: 'Iso'). A beer bitterness of $25 \mathrm{ppm}$ iso- $\alpha$-acids in the final beer was the target. Therefore, $3.85 \mathrm{~g}$ iso- $\alpha$-acids/ $\mathrm{hL}$ (presumed utilisation: $65 \%$ ) was added at the end of wort boiling.

The brew was divided and differentiated by aromatising with hops via (1) conventional late-hopping (10 min before end of boil) of part of the brew with pellets Spalter Select (127 g/hL) (code: 'Iso-late'), (2) conventional dryhopping with pellets Spalter Select $(60 \mathrm{~g} / 50 \mathrm{~L})$ (code: 'Iso-dry'), and (3) aromatisation upon beer filtration, using total hop oil (code: 'Iso-total') and fractionated hop oils (i.e., polar (code: 'Iso-polar'), floral (code: 'Iso-floral'), and spicy (code: 'Iso-spicy') hop oils extracted from cv. Spalter Select), respectively (for additional details, see Table I).

Brew 3: non-bittered beer (code: 'Non'). A third basic brew was not bittered, but exclusively aromatised with hops via (1) conventional dry-hopping with pellets Spalter Select (60 g/50 L) (code: 'Non-dry'), and (2) advanced aromatisation upon beer filtration, using total hop oil (code: Non-total) and fractionated hop oils (i.e., polar (code: 'Non-polar'), floral (code: 'Non-floral'), and spicy (code: 'Non-spicy') hop oils extracted from cv. Spalter Select), respectively (for additional details, see Table I).

\section{Determination of hop oil constituents in beer}

Extraction of hop oil constituents by solid phase microextraction (SPME). A volume of $5 \mathrm{~mL}$ of beer was placed into a $12 \mathrm{~mL}$ glass vial, which was closed with a PTFE-coated septum. Volatile compounds were extracted by inserting a polydimethylsiloxane fibre (PDMS, 100 $\mu \mathrm{m}$, Supelco, Bellefonte, PA, USA) into the vial headspace. Extraction temperature and time were set at $40^{\circ} \mathrm{C}$ for $30 \mathrm{~min}$ in the case of extracting linalool. For isolation of oxygenated sesquiterpenes, the extraction temperature was set at $60^{\circ} \mathrm{C}$ and total extraction time was $60 \mathrm{~min}$. Before the extraction started, the samples were pre-incubated at the respective temperatures for $5 \mathrm{~min}$. During pre-incubation and actual extraction, samples were stirred at 500 rpm. Extractions were fully automated using the CombiPal autosampler (CTC Analytics, Switzerland).

GC-MS conditions for separation and detection of the extracted volatiles. Gas chromatographic conditions were as follows. Extracted volatiles were thermally desorbed in the heated inlet $\left(250^{\circ} \mathrm{C}\right)$ of a Thermo Ultra Trace Gas Chromatograph (Interscience, Belgium) for 3 min. Helium (Alphagaz 2, Air Liquide, Belgium) was used as a carrier gas at a constant flow of $0.8 \mathrm{~mL} / \mathrm{min}$. Injection was conducted in the splitless mode for $3 \mathrm{~min}$ at $250^{\circ} \mathrm{C}$. Separation of the injected compounds was performed on a $40 \mathrm{~m} \times 0.18 \mathrm{~mm}$ i.d. $\times 0.2 \mu \mathrm{m}$ RTX-1 capillary column (Restek Corporation, Bellefonte, PA, USA).

Table I. Overview of the different basic brews and beers derived thereof.

\begin{tabular}{|c|c|c|c|c|c|}
\hline \multicolumn{6}{|c|}{ CONVENTIONAL BITTERING } \\
\hline Beer code & Hop product & Time of addition & Aimed bitterness & $\alpha$-acids & Addition \\
\hline Con-pel & Pellets T90 cv. Magnum & Start of boil & $25 \mathrm{ppm}$ iso & $10.5 \%(\mathrm{w} / \mathrm{w})$ & $74.4 \mathrm{~g} / \mathrm{hL}$ \\
\hline Con- $\mathrm{CO}_{2}$ & $\begin{array}{c}\text { Carbon dioxide extract cv. } \\
\text { Magnum }\end{array}$ & Start of boil & $25 \mathrm{ppm}$ iso & $43.4 \%(w / w)$ & $17.5 \mathrm{~g} / \mathrm{hL}$ \\
\hline \multicolumn{6}{|c|}{ ADVANCED HOPPING: BITTERING AND AROMATISATION } \\
\hline Beer code ca $^{a}$ & $\begin{array}{l}\text { (Fractionated) hop oils used } \\
\text { for aromatisation }\end{array}$ & Time of addition & Standard addition rates (FID) & \multicolumn{2}{|c|}{ Cask volume } \\
\hline Iso ${ }^{\mathrm{c}}$-blank & $-d$ & - & - & \multicolumn{2}{|c|}{$50 \mathrm{~L}$} \\
\hline Non-blank & - & - & - & \multicolumn{2}{|c|}{$50 \mathrm{~L}$} \\
\hline Iso ${ }^{c}$-total & Total hop oil & Post-filtration & $0.6 \mathrm{mg}$ volatiles $/ \mathrm{L}$ of beer & \multicolumn{2}{|c|}{$50 \mathrm{~L}$} \\
\hline Non-total & Total hop oil & & & \multicolumn{2}{|c|}{$50 \mathrm{~L}$} \\
\hline Iso ${ }^{c}$-polar & Polar fraction & Post-filtration & $20 \mu \mathrm{g}$ spicy components/L of beer & \multicolumn{2}{|c|}{$30 \mathrm{~L}$} \\
\hline Non-polar & Polar fraction & & & \multicolumn{2}{|c|}{$30 \mathrm{~L}$} \\
\hline Iso $^{\mathrm{c}}$-floral & Floral essence & Post-filtration & $20 \mu \mathrm{g}$ floral components/L of beer & \multicolumn{2}{|c|}{$50 \mathrm{~L}$} \\
\hline Non-floral & Floral essence & & & \multicolumn{2}{|c|}{$50 \mathrm{~L}$} \\
\hline Iso $^{c}$-spicy & Spicy essence & Post-filtration & $20 \mu \mathrm{g}$ spicy components/L of beer & \multirow{2}{*}{\multicolumn{2}{|c|}{$30 \mathrm{~L}$}} \\
\hline Non-spicy & Spicy essence & & & & \\
\hline \multicolumn{6}{|c|}{ ADVANCED BITTERING AND CONVENTIONAL AROMATISATION } \\
\hline Beer code & Hop product & Time of addition & Addition rate & \multicolumn{2}{|c|}{ Cask volume } \\
\hline Iso-late & Pellets T90 cv. Spalter Select & $\begin{array}{l}10 \text { min before end } \\
\text { of boiling }\end{array}$ & $127 \mathrm{~g} / \mathrm{hL}$ & \multicolumn{2}{|c|}{$\begin{array}{l}50 \mathrm{~L} \\
50 \mathrm{~L}\end{array}$} \\
\hline Iso ${ }^{c}$-dry & Pellets T90 cv. Spalter Select & Lagering & $60 \mathrm{~g} / 50 \mathrm{~L}$ & \multicolumn{2}{|c|}{$50 \mathrm{~L}$} \\
\hline Non-dry & & Lagering & $60 \mathrm{~g} / 50 \mathrm{~L}$ & \multicolumn{2}{|c|}{$50 \mathrm{~L}$} \\
\hline
\end{tabular}


The oven temperature program for determination of linalool was as follows: $3 \mathrm{~min}$ at $35^{\circ} \mathrm{C}$, followed by a temperature increase of $5^{\circ} \mathrm{C} / \mathrm{min}$ up to $250^{\circ} \mathrm{C}$ ( $1 \mathrm{~min}$ isotherm). For determination of sesquiterpenoids, the following oven program was used: $1 \mathrm{~min}$ at $40^{\circ} \mathrm{C}$, increase of temperature at $10^{\circ} \mathrm{C} / \mathrm{min}$ up to $200^{\circ} \mathrm{C}$, then at $3^{\circ} \mathrm{C} / \mathrm{min}$ up to a final temperature of $260^{\circ} \mathrm{C}$ (3 min isotherm).

For selective determination and precise quantification of linalool in wort and beer samples, an ion trap mass detector (Thermo Scientific ITQ 1100, Interscience, Belgium) operating in the electron ionisation mode (EI, 70 $\mathrm{eV}$ ) was used. The ion source temperature was set at $240^{\circ} \mathrm{C}$ and the electron multiplier voltage was $1,200 \mathrm{~V}$. Analyses were performed by operating in the MS/MS mode. The fragment ion with $\mathrm{m} / \mathrm{z}=121$ was isolated and further fragmented by collision induced dissociation (CID, 2.0). The resulting daughter ion with $\mathrm{m} / \mathrm{z}=105$ was selected for quantification of the linalool content in beer.

Mass spectrometric detection of sesquiterpenoids in beer samples was obtained using a dual stage quadrupole MS (Thermo Scientific DSQ I, Interscience, Belgium) operating in the electron ionisation mode (EI, $70 \mathrm{eV}$ ). The ion source temperature was set at $240^{\circ} \mathrm{C}$ and the electron multiplier voltage was $1,445 \mathrm{~V}$. Analyses were performed in both full scan mode $(\mathrm{m} / \mathrm{z}=40-400)$ and selected ion monitoring (SIM) mode. The following fragment ions were selected for detection of sesquiterpenoids in the SIM mode: $\mathrm{m} / \mathrm{z}=67,81,82,93,138,161,204,220$, and 222 . The identity of the compounds was confirmed by mass spectral comparison using the NIST98 library, retention times of standards, and calculation of retention indices. Retention indices were determined by SPME extraction of a solution of a homologous series of normal alkanes (C8C18) and subsequent GC-analysis. Semi-quantitative data on the sesquiterpenoids were obtained by standard addition of a caryophyllene oxide standard (99\%, SigmaAldrich, Steinheim, Germany) to the beer samples and, consequently, the concentration of the marker sesquiterpenoids is expressed as $\mu \mathrm{g}$ caryophyllene oxide equivalents/L beer.

\section{Determination of bittering principles}

Quantitative analysis of iso- $\alpha$-acids in beer was performed by HPLC of beer extracts on a Hitachi Liquid Chromatograph (Merck, Darmstadt, Germany), according to De Cooman et al. ${ }^{4}$ The HPLC consists of a programmable HPLC pump (L-7100) with a quaternary low pressure gradient system, a diode array detector (L-7450A), an interface module (D-7000), a solvent degasser (L7612), an autosampler (L-7200), and an Alltima $5 \mu \mathrm{m} \mathrm{C18}$ column (150 mm $\times 4.6 \mathrm{~mm}$ i.d.; Alltech Associates, Deerfield, USA). A dicyclohexylamine-iso- $\alpha$-acids ICS-I1 complex $(66.5 \%$ (w/w) iso- $\alpha$-acids) (Labor Veritas, Zürich, Switzerland) was used for quantitative determination of iso- $\alpha$-acids (additional details on HPLC analysis of iso- $\alpha$-acids are given in the references ${ }^{4,17}$ ).

\section{Sensory evaluation of pilot beers}

Sensory evaluations of the pilot beers investigated in this study were performed by the trained taste panel (12 members) of our institute.
Fresh beers. Triangular tests were carried out for objective recognition of the potential flavour effect of hop aromatisation in (1) an advanced way, i.e., by addition of well defined amounts of particular hop oil preparations, or (2) a conventional way, i.e., by addition of hop pellets at the end of the boil or during lagering. In every session, the non-aromatised reference beer (Iso-blank or Non-blank) was compared to a particular aromatised beer derived from the same basic brew.

Next to triangular tests, descriptive analyses were performed in different series. In a first session, the conventionally bittered beers (Con-pel and Con- $\mathrm{CO}_{2}$ ) and the blank iso- bittered beer were evaluated. In a second and third session, the blank iso-bittered beer was offered in a series with the advanced aromatised beers (Iso-floral, Isopolar, Iso-total, Iso-spicy) and conventionally aromatised beers (Iso-late, Iso-dry), respectively. The focus of these sessions was on the intensity and the sensory description of hoppy aroma of the beers. Intensity scores for hoppy aroma were given on a scale from 0 (no hoppy aroma) to 8 (very strong hoppy aroma). Furthermore, panellists were asked to describe hoppy aroma in terms of 'floral', 'citrus', 'herbal', 'spicy', 'dry-hop aroma', 'kettle hop aroma', or 'fresh hops'. In addition, they were asked to evaluate bitterness intensity and quality, and the effect on mouthfeel (in particular fullness) by giving scores from 0 (not perceptible, very bad quality) to 8 (very high intensity, superb quality).

Aged beers. Beers were evaluated for flavour staling by giving overall ageing scores from 0 (completely fresh) to 8 (very strongly aged, undrinkable). Sensory assessment of staling was performed in nine different taste sessions. Each session was comprised of the fresh beer (stored at $0^{\circ} \mathrm{C}$ ) and samples of the same beer that had been aged at $30^{\circ} \mathrm{C}$ for 30 and 60 days, respectively (e.g., Session 1: Iso-blank fresh, Iso-blank 30 days, Iso-blank 60 days).

\section{RESULTS AND DISCUSSION}

In this comparative study, pilot Pilsner beers were hopped by applying different technologies and hop products. Hop pellets T90 or non-isomerised hop extract were used at the onset of wort boiling mainly to obtain bitterness and/or kettle hop aroma in the conventional way. On the other hand, a series of Pilsner beers were made by imparting both bitterness and hop-derived aroma in an advanced way, i.e., by using iso- $\alpha$-acids extract and novel hop oil preparations, respectively. For that purpose, one basic brew, exclusively bittered with iso- $\alpha$-acids extract at the end of the boil was further differentiated post-filtration by well-defined amounts of novel SFE/SPE hop oil preparations. Moreover, part of this basic brew was late-hopped or dry-hopped by using aroma hop pellets T90 at the end of boiling or during maturation, respectively. As a reference, a third non-bittered basic brew was prepared and differentiated by applying the same advanced hop oil preparations and conventional dry-hopping. More details on the brews and their particular hopping are given in the 'Materials and Methods' section and in Table I. 


\section{Conventional bittering: quantitative aspects of linalool as a function of beer preparation}

For the conventionally bittered beers, the level of linalool was monitored by HS-SPME in combination with GC-MS/MS along the brewing process, starting from the onset of wort boiling to the finished beer (Fig. 1). Aiming at a final beer bitterness of $25 \mathrm{ppm}$ iso- $\alpha$-acids by single hop addition at the beginning of the boil, it is obvious that the amount of linalool added to the wort depends on the hop product. In our brewing trials, when using hop pellets T90 cv. Magnum, $35.0 \mu \mathrm{g}$ linalool was theoretically introduced to one litre of wort at the start of boiling, compared to $50.6 \mu \mathrm{g}$ linalool/L when using non-isomerised hop extract from the same variety. Notwithstanding this significant difference, the level of linalool in the finished beers was very similar, i.e., $2.3 \mu \mathrm{g} / \mathrm{L}$ for both the pellet and extract hopped beer (Fig. 1). This finding clearly suggests that the initial linalool content is lost to a great extent during beer preparation, in particular as can be noticed in Fig. 1 during wort boiling due to evaporation. Furthermore, in our experiments a significantly higher linalool concentration was observed at the end of the boil and in the pitching wort when using non-isomerised hop extract, whereas after the main fermentation and (as mentioned earlier) in the finished beers, the level of linalool was comparable for both conventionally hopped brews. When comparing early hop addition using non-isomerised extract or hop pellets, Mitter et al. ${ }^{30}$ observed a different behaviour of linalool during wort boiling due to the fact that hop extracts dissolve very slowly. This phenomenon may (partly) explain the higher content of linalool at the end of boiling when using hop extract in our study. Furthermore, according to Kaltner and Mitter $^{20}$ a typical phenomenon of classic boiling systems is that the linalool concentration in the wort at the end of boiling is highly comparable to the final concentration detected in the resulting beer. This however was only true for our pellet hopped pilot beer.

An increase in the linalool concentration upon fermentation, due to liberation of glycosidically bound linalool $^{3,14}$, was not observed in this study; though according to the literature ${ }^{2,25}$ in contrast to non-isomerised hop extract, glycosidically bound linalool is introduced into the boiling wort when using hop pellets.

Different flavour threshold values have been reported for linalool. According to Kaltner et al. ${ }^{22,23}$, the flavour threshold of linalool is $5-10 \mu \mathrm{g} / \mathrm{L}$ in Pilsner beer. Steinhaus et al. ${ }^{35}$ reported odour threshold values for both $(R)$ - and $(S)$-linalool. The odour threshold for $(R)$-linalool, the most flavour-active species, has been determined at $2.2 \mu \mathrm{g} / \mathrm{L}$ in beer and $0.14 \mu \mathrm{g} / \mathrm{L}$ in water. $(S)$-linalool is much less flavour active with its threshold value determined at $180 \mu \mathrm{g} / \mathrm{L}$ and $2.9 \mathrm{ng} / \mathrm{L}$ in beer and air, respectively.

Thus, when considering linalool as an analytical marker for the intensity of hoppy aroma, it is expected from the low levels measured in our conventionally hopped pilot beers that hoppy aroma will be far from pronounced. In our study, the enantiomeric distribution of linalool in the finished pilot beers was not determined, but the finding that the linalool concentration (i.e., the sum of $(R)$ - and (S)-linalool) was comparable to the threshold value of $(R)$-linalool $(2.2 \mu \mathrm{g} / \mathrm{L})$, allows one to assume that linalool will not be a significant contributor to the odour

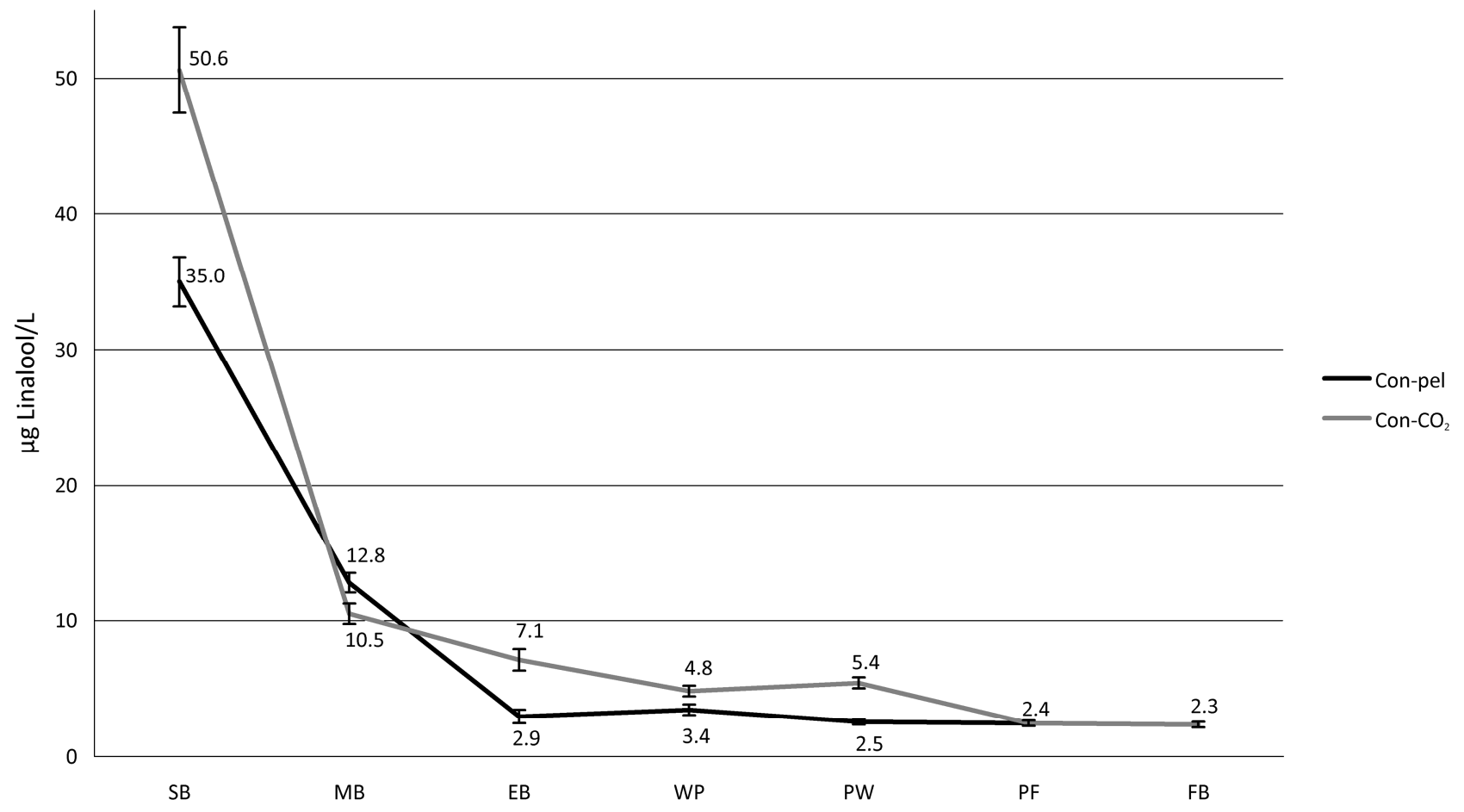

Fig. 1. Evolution of the linalool concentration when applying conventional hopping with either pellets T90 or carbon dioxide extract at the onset of wort boiling (points of sampling: SB: start boil; MB: mid of boil (30 min after hop addition); EB: end of boil (60 min after hop addition); WP: whirlpool; PW: pitching wort; PF: after 1 week of fermentation; FB: finished beer) (mean of 5 determinations for each point; $95 \%$ confidence intervals). 


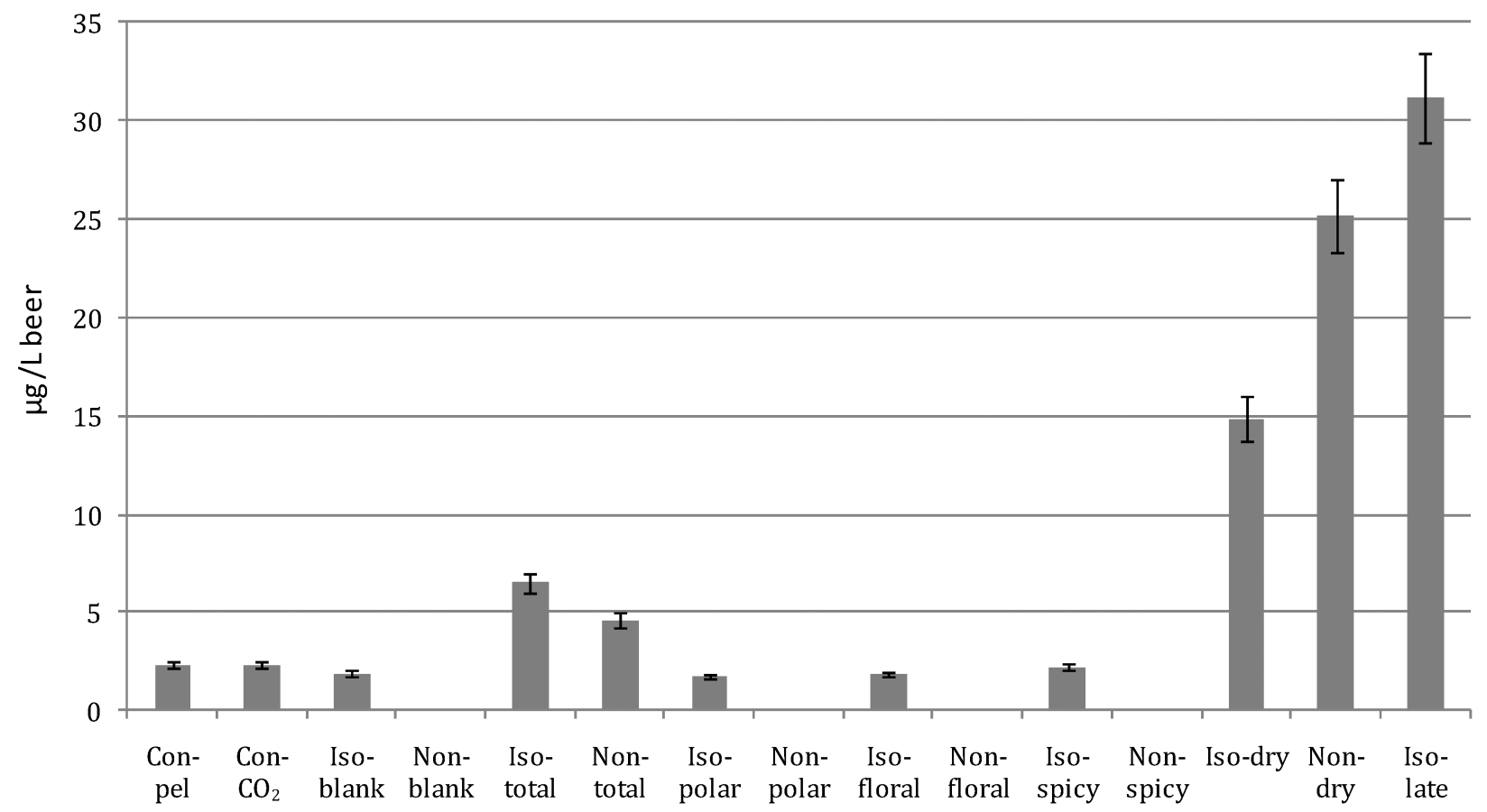

Fig. 2. Overview of the linalool concentration in the fresh conventionally hopped, advanced hopped, and non-bittered pilot beers (mean of 5 determinations, $95 \%$ confidence intervals).

of the conventionally bittered pilot beers. Moreover, since Steinhaus et al. ${ }^{35}$ determined the enantiomeric distribution of linalool in finished early kettle hopped beers at 52:48 and 59:41 (\% ratio R-enantiomer/S-enantiomer), the level of $(R)$-linalool in the final beers of our study was expected to be lower than the threshold value of $2.2 \mu \mathrm{g} / \mathrm{L}$.

\section{Advanced hopping: quantitative aspects of linalool in fresh pilot beers}

The linalool concentration in the finished beers prepared during this study is displayed in Fig. 2 (for hopping regimes see Table I). Clearly, the level of linalool in finished beer depends on the applied hopping technology and on the type of hop oil fraction used. When comparing the different beers, it was clear that advanced aromatisation with total hop oil and conventional aromatisation with pellets (either late or dry-hopping) gave rise to the highest levels of linalool. Dry-hopping results in a linalool concentration of $14.5 \mu \mathrm{g} / \mathrm{L}$ and $25.2 \mu \mathrm{g} / \mathrm{L}$ in the fresh isobittered beer (Iso-dry) and non-bittered beer (Non-dry), respectively. The most pronounced effect was obtained by late-hopping of the brew bittered with iso- $\alpha$-acids extract, resulting in a linalool content of $31.2 \mu \mathrm{g} / \mathrm{L}$ in the final beer (Iso-late). This value clearly exceeds the flavour threshold of 5-10 $\mu \mathrm{g} / \mathrm{L}$ and thus a clear impact on hoppy aroma can be expected. Using total hop oil from pellets T90 cv. Spalter Select, resulted in $6.5 \mu \mathrm{g}$ linalool/L beer (Iso-total) and $4.6 \mu \mathrm{g}$ linalool/L beer (Non-total), respectively.

On the other hand, linalool was not detected in the non-bittered basic beer (Non-blank), or in the non-bittered beers aromatised with polar (Non-polar), floral (Non-floral), and spicy (Non-spicy) hop essences, respectively. Indeed, HS-SPME-GC-MS analysis of the polar, floral, and spicy hop essences showed that these particular hop

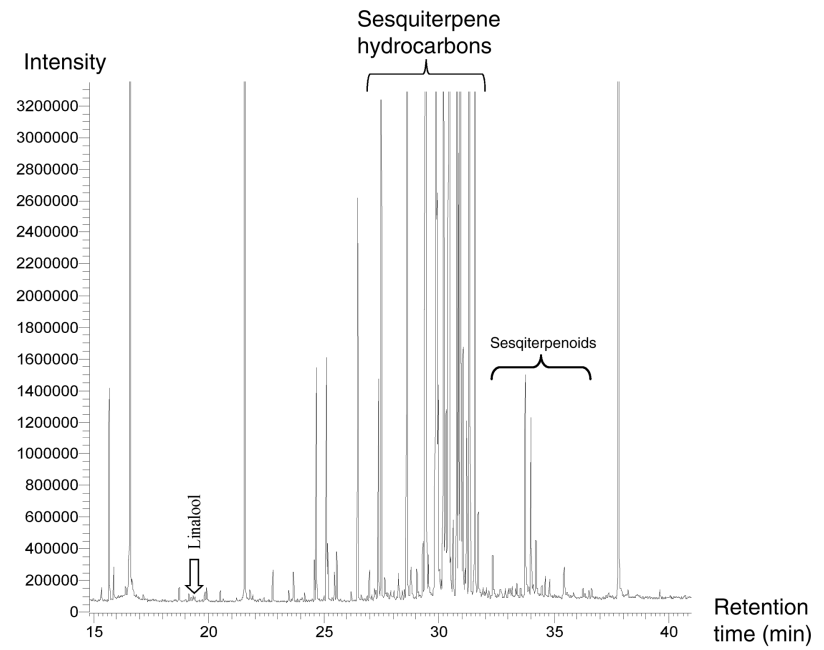

Fig. 3. GC-MS fingerprint of the volatile composition of iso- $\alpha-$ acids extract.

oil preparations do not contain linalool. An interesting observation is that the non-aromatised iso-bittered beer (Iso-blank) and iso-bittered beers aromatised with polar (Iso-polar), floral (Iso-floral), or spicy (Iso-spicy) essence, do contain linalool, albeit in low levels $(1.9 \mu \mathrm{g} / \mathrm{L}$ on average). The only possible way to introduce linalool into these beers would have been via the iso- $\alpha$-acids extract used for bittering. Evidence for this was obtained by analysis of the volatile fraction of the iso- $\alpha$-acids extract by HS-SPME-GC-MS (Fig. 3). Clearly, next to other hop oil constituents (e.g., sesquiterpenes), linalool is present in the isomerised hop extract $(27.1 \pm 2.2 \mu \mathrm{g}$ linalool $/ \mathrm{g}$ extract). Thus, when using an iso- $\alpha$-acids extract for bittering purposes, hop essential oil constituents are intro- 
Table II. Concentration of marker sesquiterpenoids (expressed as $\mu$ g caryophyllene oxide equivalents/Litre beer) in conventionally and advanced hopped Pilsner beers ${ }^{\mathrm{a}}$.

\begin{tabular}{|c|c|c|c|c|c|c|c|c|c|c|}
\hline & $\mathbf{R I}^{\mathbf{b}}$ & Con-pel & $\mathrm{Con}-\mathrm{CO}_{2}$ & Iso-blank & Iso-total & Iso-polar & Iso-floral & Iso-spicy & Iso-dry & Iso-late \\
\hline $\begin{array}{l}\text { caryophyllene oxide } \\
\text { unidentified }\end{array}$ & 1571 & 2.6 & 2.0 & 1.4 & 6.0 & 3.0 & 2.0 & 2.6 & 5.2 & 3.6 \\
\hline sesquiterpenoid & 1581 & 1.0 & 1.8 & 0.0 & 4.6 & 1.9 & 1.0 & 1.9 & 6.9 & 3.9 \\
\hline humulene epoxide I & 1595 & 6.9 & 10.3 & 2.0 & 13.6 & 4.6 & 1.9 & 4.1 & 12.9 & 8.0 \\
\hline humulene epoxide II & 1605 & 3.8 & 4.9 & 2.0 & 8.6 & 3.9 & 1.6 & 4.5 & 11.7 & 6.6 \\
\hline$\beta$-eudesmol ${ }^{\mathrm{c}}$ & 1637 & 31.0 & 31.8 & 10.1 & 115.9 & 56.8 & 12.5 & 48.3 & 108.3 & 64.2 \\
\hline humulenol II ${ }^{\mathrm{c}}$ & 1627 & & & & & & & & & \\
\hline $\begin{array}{l}\text { humulene epoxide III } \\
\text { unidentified }\end{array}$ & 1625 & & & & & & & & & \\
\hline sesquiterpenoids & 1646 & 2.3 & 3.3 & 1.8 & 15.4 & 8.1 & 2.6 & 10.3 & 51.1 & 35.4 \\
\hline Total & & 47.6 & 54.1 & 17.3 & 164.1 & 78.3 & 21.6 & 71.7 & 196.1 & 121.7 \\
\hline & RI & & & Non-blank & Non-total & Non-polar & Non-floral & Non-spicy & Non-dry & \\
\hline $\begin{array}{l}\text { caryophyllene oxide } \\
\text { unidentified }\end{array}$ & 1571 & & & 0.0 & 4.7 & 1.7 & 0.4 & 1.2 & 4.2 & \\
\hline sesquiterpenoid & 1581 & & & 0.0 & 5.0 & 1.6 & 0.9 & 1.8 & 7.3 & \\
\hline humulene epoxide I & 1595 & & & 0.0 & 11.3 & 2.3 & 0.0 & 2.1 & 10.0 & \\
\hline humulene epoxide II & 1605 & & & 0.0 & 6.3 & 1.9 & 0.0 & 2.3 & 10.5 & \\
\hline$\beta$-eudesmol ${ }^{\mathrm{c}}$ & 1637 & & & 0.0 & 103.5 & 45.8 & 2.3 & 37.6 & 95.7 & \\
\hline humulenol $\mathrm{II}^{\mathrm{c}}$ & 1627 & & & & & & & & & \\
\hline $\begin{array}{l}\text { humulene epoxide } \text { III }^{\mathrm{c}} \\
\text { unidentified }\end{array}$ & 1625 & & & & & & & & & \\
\hline sesquiterpenoids & 1646 & & & 0.0 & 18.7 & 6.3 & 0.7 & 9.3 & 19.3 & \\
\hline Total & & & & 0.0 & 149.5 & 59.6 & 4.3 & 54.3 & 147.0 & \\
\hline
\end{tabular}

${ }^{\text {a }}$ For hopping regimes, see Table I.

${ }^{\mathrm{b}}$ Retention index.

${ }^{\mathrm{c}}$ Co-eluting peaks.

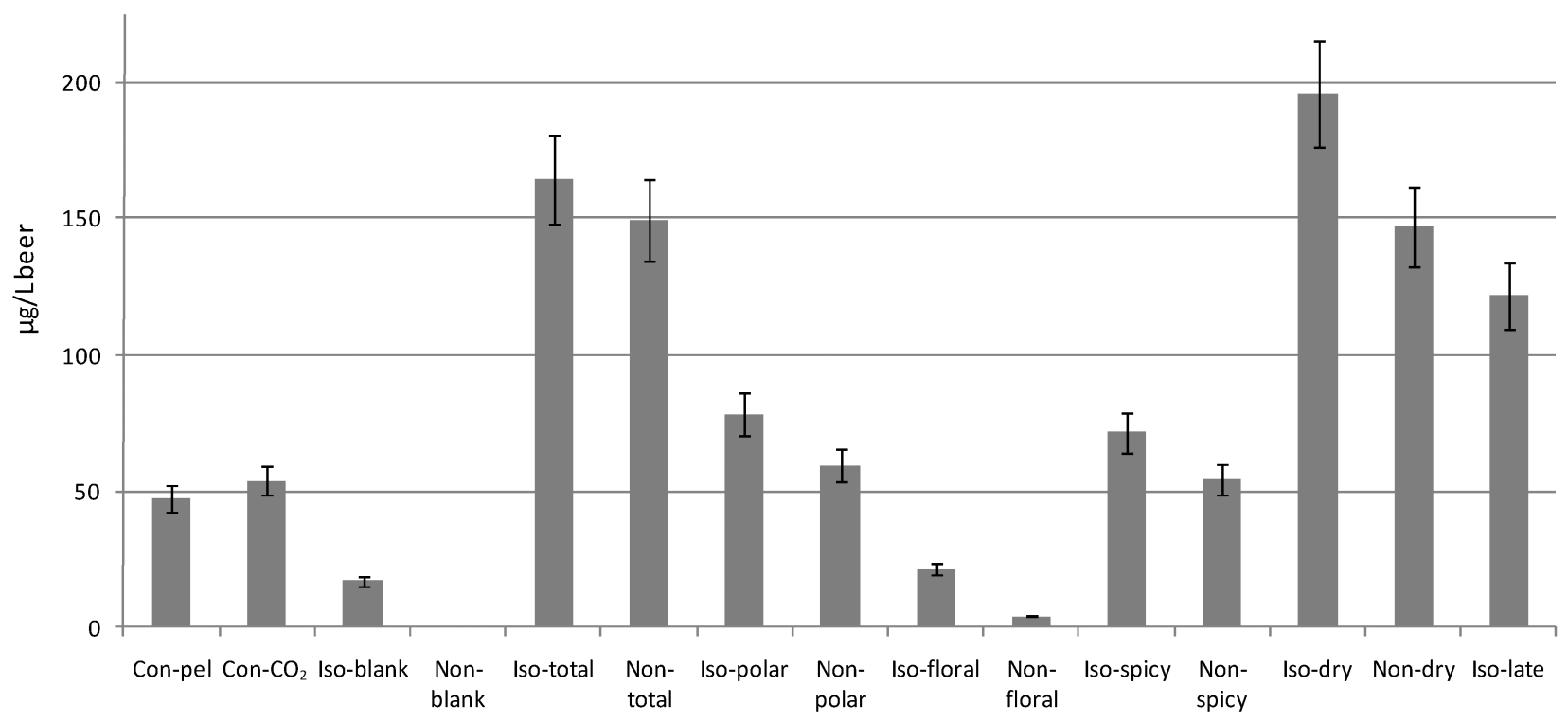

Fig. 4. Total amount of marker sesquiterpenoids in the fresh conventionally hopped, advanced hopped, and non-bittered pilot beers (mean of 5 determinations, $95 \%$ confidence intervals).

duced into the beer, which may depending on their level affect final beer flavour.

\section{Determination of hop sesquiterpenoids in fresh pilot beers}

The concentration of individual marker compounds of the sesquiterpenoid fraction in all pilot beers is given in Table II. Figure 4 shows the total amount of marker sesquiterpenoids in the different beers. Clearly, the level of the selected marker sesquiterpenoids depends on the hop- ping technology and on the hop oil fraction used for aromatisation. The sesquiterpenoid content in the beers ranged from $0.0 \mu \mathrm{g} / \mathrm{L}$ in the completely unhopped beer (Non-blank) to $196.1 \mu \mathrm{g} / \mathrm{L}$ in the dry-hopped iso-bittered beer (Iso-dry). The highest sesquiterpenoid content was observed when applying conventional aromatisation, i.e., late-hopping or dry-hopping with pellets, or when aromatising beer with total hop essential oil. A significant amount of sesquiterpenoids was also introduced when aromatising the iso-bittered and non-bittered beer in an 
advanced way by adding polar or spicy hop essences. The sesquiterpenoid content in the early kettle hopped beers was relatively low and comparable.

In accordance with our findings on linalool, application of an iso- $\alpha$-acids extract as such also introduces sesquiterpenoids into the beer. Indeed, the non-aromatised iso-bittered reference beer (Iso-blank) contained 17.3 $\mu$ g marker sesquiterpenoids per litre of beer (also see Fig 3 for the presence of sesquiterpenoids in the iso- $\alpha$-acids extract). Furthermore, when comparing advanced aromatisation of the iso-bittered brew with the non-bittered brew, and when the amount of sesquiterpenoids introduced by the iso- $\alpha$-acids extract is taken into account, it can be concluded that advanced aromatisation of the beers with our hop oil fractions after beer filtration was highly reproducible.

\section{Sensory evaluation of fresh pilot beers}

Sensory evaluation of all fresh beers through descriptive and triangular taste sessions was performed by the trained taste panel of our institute (for procedures, see section 'Materials and Methods').

Triangular tests were carried out for determination of sensory differences in the flavour profile of the differently hopped pilot beers. Thus, in all of these sessions, a nonaromatised reference beer (either Iso-blank or Non-blank) was compared to an aromatised beer. In summary, all triangular tests gave conclusive evidence for significant differences in the sensory profile of reference and aromatised beers (data not shown). In other words, whether dosing hop oil essences after beer filtration or performing conventional aromatisation, clearly perceptible flavour changes to the reference beer were always observed.

The results of the descriptive sensory analyses of the experimental Pilsner beers, in respect to hoppy aroma, bitterness, and mouthfeel, are summarised in Table III. Intensity scores for hoppy aroma of the different beers ranged from 0.5 (hardly perceptible) for the non-aromatised iso-bittered beer to 5.4 (clearly present) for the latehopped iso-bittered beer. Hoppy aroma is described in terms of 'kettle hop aroma', 'floral', 'citrus', 'green', 'fresh hops', and 'dry-hop'. Clearly, both the intensity and the description of hoppy aroma depend on the hopping technology and on the hop oil fraction used for aromatisation. Both conventionally hopped beers showed a relatively poor and comparable hoppy aroma, described as 'kettle hop aroma'. Whereas the advanced bittered refer- ence brew (Iso-blank) showed almost no hoppy aroma, all of the advanced or conventionally aromatised beers derived from the iso-bittered basic brew were clearly characterised by a hoppy aroma impression. Addition of the respective hop oil fractions post beer filtration, as well as addition of pellets at the end of boiling or during lagering imparted a clearly perceptible, distinct, and pleasant, but not too overwhelming hoppy aroma character to the corresponding beers.

Next to the contribution to hoppy aroma, it is further interesting to note from Table III that the sensory impact of adding hop oil fractions was not only limited to beer aroma. Indeed, hop aromatisation also affected bitterness perception and mouthfeel. In particular, application of spicy hop essence had a clear impact on the bitterness perception of the beer (Iso-spicy), in that bitterness intensity increased in comparison to the blank beer (Iso-blank), while bitterness quality remained similar. The same held true for advanced aromatisation with the polar hop essence (Iso-polar) and for conventional late-hopping (Isolate), although conventional late hopping resulted in some decline in bitterness quality, due to lingering bitterness.

On the other hand, the floral hop essence (Iso-floral) affected bitterness perception in that the intensity was scored lower compared to the blank beer (Iso-blank). When considering mouthfeel of the beers, the sensory results point to enhancement of fullness when hop aromatisation is applied. In accordance to the synergistic effect on bitterness perception as mentioned above, it is again the spicy hop essence that shows the most pronounced positive effect on fullness. These findings fully confirm our earlier observations on the positive impact on beer bitterness and mouthfeel of highly enriched spicy hop essences $^{11}$. The effect of commercial hop oil preparations on mouthfeel attributes has also been reported by Marriott ${ }^{29}$ and Hughes ${ }^{15}$. In accordance with the observations on our in-house prepared hop oil essences, the sensory impact on beer mouthfeel of commercial preparations clearly depends on the type of added fractionated hop oil (e.g., PHA floral, PHA herbal, ...).

When considering the use of linalool as an analytical marker for hoppy aroma (Fig. 2), it was observed that a high hoppy aroma intensity (Table III) was not always reflected by a high level of linalool in the beer. Indeed, for the advanced bittered and conventionally aromatised beers (i.e., dry- or late-hopping), a relatively high score for hoppy aroma intensity corresponded to a high content in

Table III. Sensory evaluation of the fresh conventionally and advanced bittered pilot beers (all scores range from 0 (not perceptible/very bad quality) to 8 (very high intensity/superb quality); bitterness quality: $\mathrm{F}=$ fine, $\mathrm{L}=$ lingering, $\mathrm{S}=$ sharp) (figures represent the mean score of 12 panellists).

\begin{tabular}{|c|c|c|c|c|c|c|c|c|c|}
\hline & Con-pel & Con-CO & Iso-blank & Iso-total & Iso-polar & Iso-floral & Iso-spicy & Iso-dry & Iso-late \\
\hline \multicolumn{10}{|c|}{ Hoppy aroma } \\
\hline Score & 2.9 & 3.1 & 0.5 & 4.5 & 5.3 & 4.2 & 4.2 & 4.9 & 5.4 \\
\hline Descriptor & kettle hop & kettle hop & & $\begin{array}{l}\text { citrus, fresh } \\
\text { hops }\end{array}$ & citrus & $\begin{array}{c}\text { floral, fresh } \\
\text { hops }\end{array}$ & $\begin{array}{c}\text { dry-hop, } \\
\text { fresh hops, } \\
\text { green }\end{array}$ & fresh hops & citrus \\
\hline \multicolumn{10}{|l|}{ Bitterness } \\
\hline Intensity & 4.9 & 4.8 & 4.8 & 5.1 & 5.8 & 4.1 & 6.1 & 4.7 & 5.5 \\
\hline Quality & 5.5 & 6.1 & 7.1 & 5.7 & 6.9 & 6.7 & 7.0 & 6.0 & 6.1 \\
\hline & $\mathrm{L}$ & $\mathrm{L}$ & $\mathrm{F}$ & $\mathrm{S} / \mathrm{L}$ & $\mathrm{F}$ & $\mathrm{L}$ & $\mathrm{F}$ & $\mathrm{L}$ & $\mathrm{L}$ \\
\hline \multicolumn{10}{|l|}{ Mouthfeel } \\
\hline Fullness & 3.8 & 3.8 & 4.0 & 4.9 & 5.1 & 4.2 & 5.8 & 4.5 & 4.8 \\
\hline
\end{tabular}


linalool, whereas hoppy aroma intensity scores for the advanced aromatised beers could not be related to the level of linalool in these beers. This is illustrated by the result obtained on the advanced hopped beer 'Iso-polar', showing an intensity score of 5.3 and a hoppy aroma description ('citrusy') comparable to that of the conventionally aromatised beer 'Iso-late'. However, the linalool concentration of the fresh beer dosed with polar hop essence (Iso-polar) only amounted to about $2 \mathrm{ppb}$, which is comparable to the blank beer (Iso-blank) showing no hoppy aroma at all, but in sharp contrast to the conventional, late hopped beer 'Iso-late' (approx. $30 \mathrm{ppb}$ of linalool). Thus, it appears that the use of linalool as analytical marker for estimation of hoppy aroma is only reliable when conventional aromatisation is performed.

The marker hop sesquiterpenoids have been related to the so-called 'spicy' and 'noble' sensory aspects of hoppy aroma $^{11}$. Although, in general, the pilot beers with relatively high levels in sesquiterpenoids also showed the highest sensory scoring for hoppy aroma, from our results it was difficult to correlate the level of selected marker compounds for this particular group of hop oil constituents with the hoppy aroma intensity scores and/or descriptors, as shown in Table III. Nevertheless, this does not imply that the sesquiterpenoid hop oil fraction may not impart hoppy flavour attributes. Our innovative in-house prepared varietal spicy hop essences were highly enriched in sesquiterpenoids ${ }^{11,37}$ and clearly affected the organoleptic properties (hoppy aroma, bitterness and mouthfeel) when used in beer aromatisation.

\section{Flavour stability assessment of the pilot beers upon forced ageing}

Linalool and sesquiterpenoids as analytical markers for hoppy aroma. The concentration of linalool and the sum of the marker sesquiterpenoids in fresh and forced aged pilot beers $\left(30\right.$ days at $30^{\circ} \mathrm{C}$ and 60 days at $30^{\circ} \mathrm{C}$, respectively) are depicted in Fig. 5 and Fig. 6.

Upon ageing, the linalool concentration did not significantly change in the conventionally hopped beers and the late-hopped advanced bittered beer, as shown by the confidence intervals (95\% confidence level). However, when dry-hopping was applied, the level of linalool clearly increased upon ageing in both the iso-bittered and the nonbittered beer. The increase in the linalool concentration after 60 days of ageing at $30^{\circ} \mathrm{C}$ was calculated to be about $30 \%$.

For pellet hopped beers an increase in linalool upon fermentation, and as in our case, during beer ageing, has been ascribed to the liberation of glycosidically bound linalool ${ }^{3,13,22,25,27}$. However, such an increase in the level of linalool was not always observed and contradictory results can be found in the literature. For example, Kaltner and Mitter $^{20}$ reported on the high stability of linalool upon beer ageing and found that the linalool concentration remained constant even after 12 months of ageing at $20^{\circ} \mathrm{C}$. Conversely, according to experiments with beers spiked with pure linalool, Peacock and Deinzer ${ }^{32}$ observed a rapid decrease in the first weeks of beer ageing, with a relative loss of $11 \%$ of the initial linalool content after

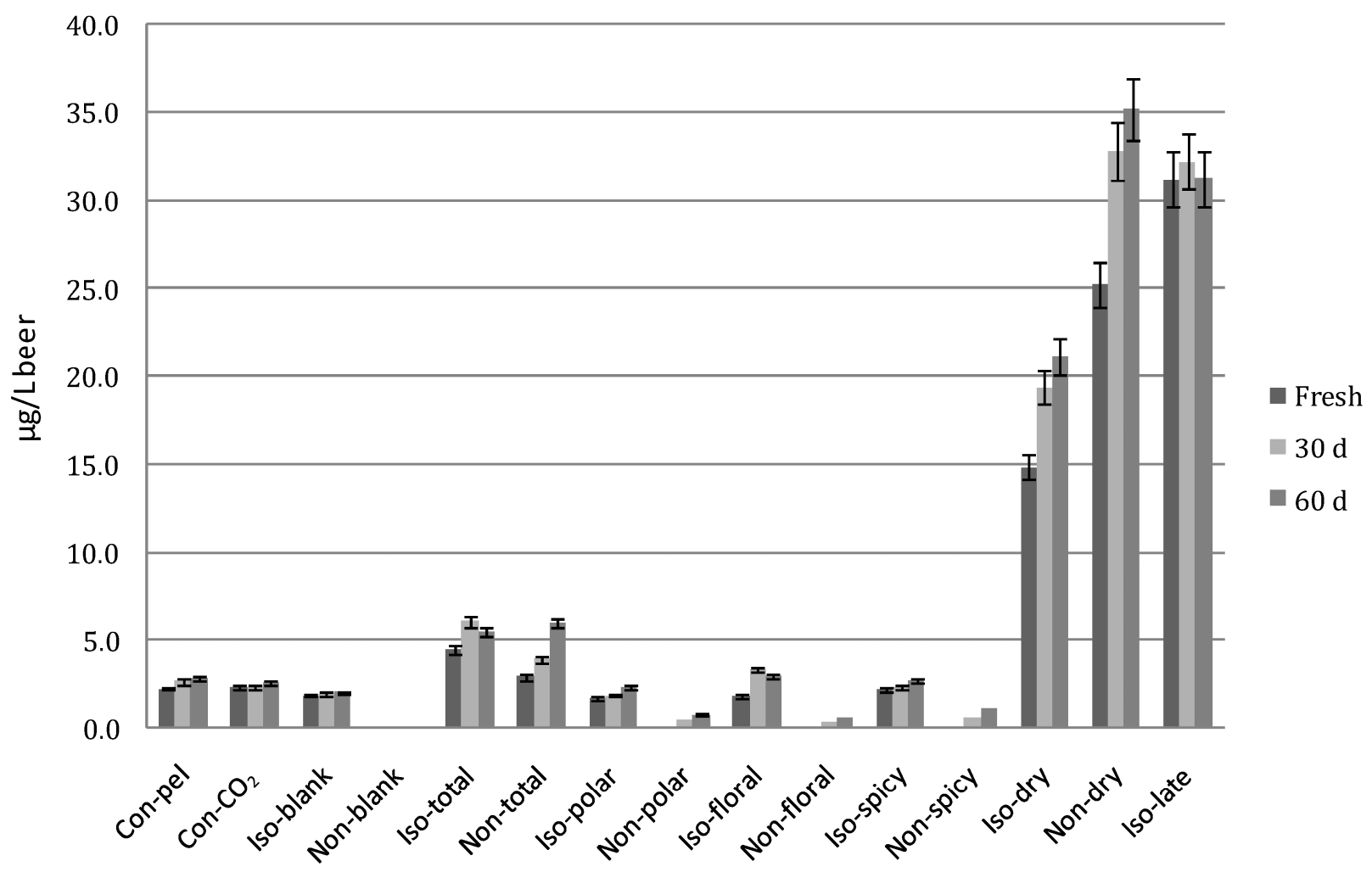

Fig. 5. Concentration of linalool (top) and marker compounds for the sesquiterpenoid hop fraction (bottom) in fresh and forced aged pilot beers ( 30 days at $30^{\circ} \mathrm{C}$ and 60 days at $30^{\circ} \mathrm{C}$, respectively) (mean of 5 determinations, $95 \%$ confidence intervals). 


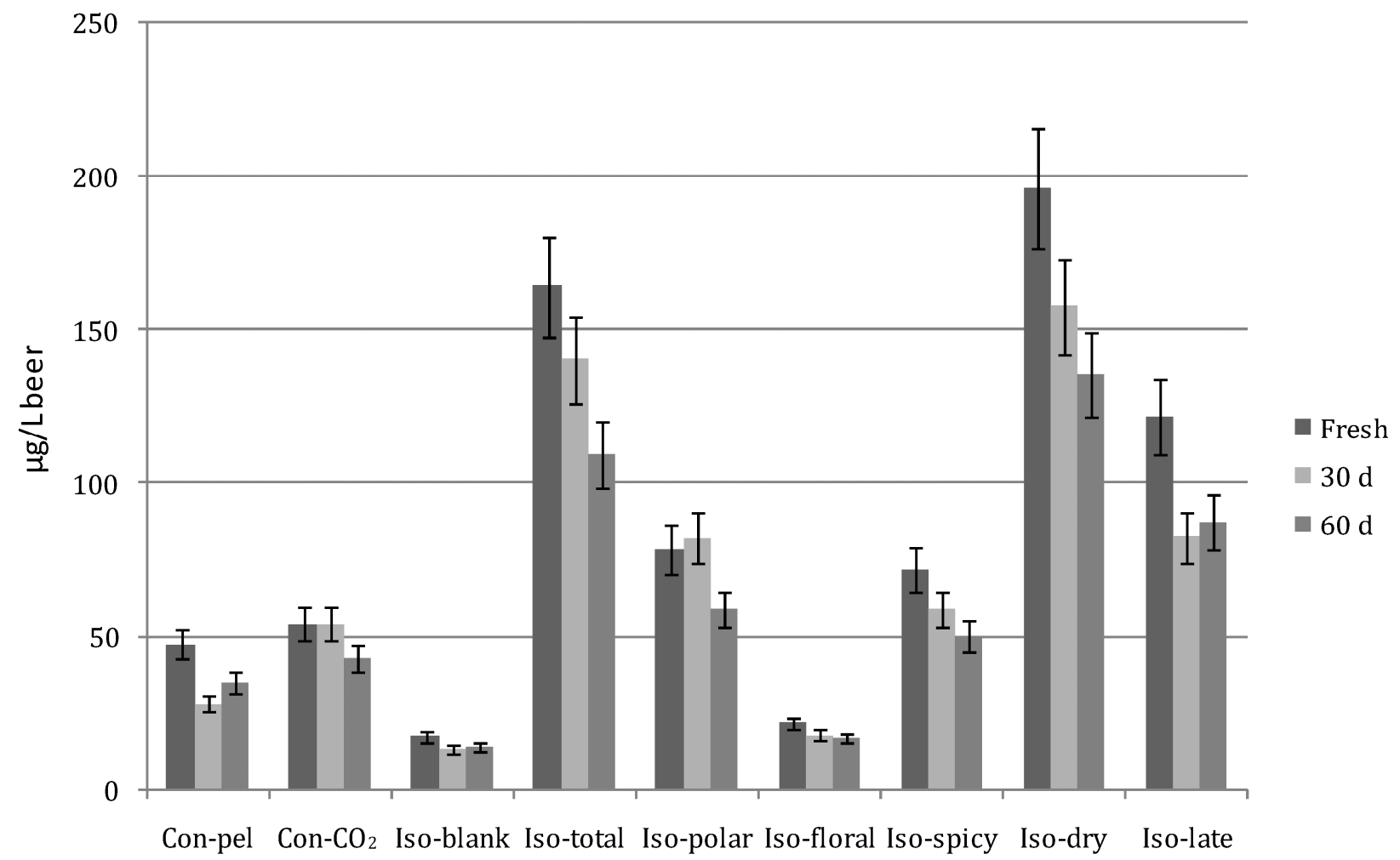

Fig. 6. Concentration of marker compounds for the sesquiterpenoid hop fraction in fresh and forced aged pilot beers $\left(30\right.$ days at $30^{\circ} \mathrm{C}$ and 60 days at $30^{\circ} \mathrm{C}$, respectively) (mean of 5 determinations, $95 \%$ confidence intervals).

Table IV. Levels of aldehyde markers for beer flavour (in)stability in fresh conventionally bittered, advanced bittered and non-bittered reference beers (mean of 3 determinations, coefficients of variation $<5 \%$ ).

\begin{tabular}{lcccc}
\hline & Con-pel $(\boldsymbol{\mu g} / \mathbf{L})$ & Con- $^{-\mathbf{C O}_{\mathbf{2}}(\boldsymbol{\mu g} / \mathbf{L})}$ & Iso-blank $(\boldsymbol{\mu g} / \mathbf{L})$ & Non-blank $(\boldsymbol{\mu g} / \mathbf{L})$ \\
\hline 2-methylpropanal & 3.7 & 4.3 & 8.5 & 5.8 \\
2-methylbutanal & 1.9 & 1.6 & 1.7 & 4.4 \\
3-methylbutanal & 7.0 & 7.9 & 8.5 & 7.7 \\
hexanal & 0.8 & 0.9 & 2.4 & 1.7 \\
trans-2-nonenal & 0.04 & 0.05 & 0.08 & 0.07 \\
furfural & 7.4 & 6.7 & 9.0 & 8.2 \\
phenylacetaldehyde & 6.6 & 6.3 & 8.0 & 12.5 \\
benzaldehyde & 1.9 & 1.7 & 3.9 & 4.6 \\
methional & 6.6 & 4.7 & 4.0 & 3.4 \\
Total & 35.9 & 34.2 & 46.1 & 48.4 \\
\hline
\end{tabular}

eight weeks of storage. Surprisingly, upon ageing the linalool concentration appeared to increase a little in all of the advanced aromatised pilot beers (Fig. 5). At this moment, an explanation for this phenomenon cannot be given since our in-house polar, floral, and spicy hop essences did not contain linalool and linalool glycosides would not be expected to be present because of the applied SFE extraction conditions ${ }^{2,25}$.

With regard to the total amount of marker sesquiterpenoids, a significant decrease can be observed for all pilot beers after 60 days of storage at $30^{\circ} \mathrm{C}$ (Fig. 6). The relative decrease measured over this time interval ranges between $20 \%$ for the early kettle hopped beer $\mathrm{Con}-\mathrm{CO}_{2}$ and $33 \%$ for the advanced hopped beer 'Iso-total'. A lower stability of sesquiterpenoids compared with linalool was observed earlier by Peacock and Deinzer ${ }^{32}$, who monitored the level of one particular sesquiterpenoid (humulenol II) in spiked beers. In their work, a decomposition of $66 \%$ of humulenol II was found after 61 days of ageing. Two mechanisms were proposed to be responsible for this fast decrease in humulenol II, i.e., oxidation by molecular oxygen and acid hydrolysis.

In conclusion, when considering analytical markers for hoppy aroma, it follows from our study that the linalool content does not decrease upon beer ageing. Instead, upon forced ageing, a significant increase in linalool was observed for the dry-hopped beers, probably due to the liberation of linalool from the glycosidic precursors that were extracted during the dry-hopping treatment. Hopderived sesquiterpenoids are clearly not stable upon beer ageing, and as may be expected from their inherent high chemical reactivity, a relatively fast and significant decrease in their levels was observed in all of the aged pilot Pilsners.

Aldehydes as analytical markers for beer staling. Next to the determination of analytical markers for hoppy aroma in fresh and aged beers as described above, marker staling aldehydes as well as the bittering principles iso- $\alpha$ - 
Table V. Levels of aldehyde markers for beer flavour (in)stability in fresh aromatised advanced bittered beers (mean of 3 determinations, coefficients of variation $<5 \%$ ).

\begin{tabular}{|c|c|c|c|c|c|}
\hline & Iso-total $(\mu \mathrm{g} / \mathrm{L})$ & Iso-polar $(\mu \mathrm{g} / \mathrm{L})$ & Iso-floral $(\mu \mathrm{g} / \mathrm{L})$ & Iso-spicy $(\mu \mathrm{g} / \mathrm{L})$ & Iso-late $(\mu \mathrm{g} / \mathrm{L})$ \\
\hline 2-methylpropanal & 5.4 & 6.4 & 6.2 & 6.1 & 4.7 \\
\hline 2-methylbutanal & 1.3 & 3.2 & 3.1 & 3.4 & 1.1 \\
\hline 3-methylbutanal & 7.3 & 6.9 & 7.3 & 8.3 & 6.2 \\
\hline hexanal & 2.2 & 0.9 & 1.1 & 1.4 & 1.3 \\
\hline trans-2-nonenal & 0.16 & 0.07 & 0.06 & 0.07 & 0.18 \\
\hline furfural & 6.4 & 6.4 & 5.4 & 5.5 & 4.7 \\
\hline phenylacetaldehyde & 7.1 & 10.4 & 11.1 & 13.2 & 7.6 \\
\hline benzaldehyde & 1.7 & 1.7 & 2.0 & 2.2 & 1.5 \\
\hline methional & 5.8 & 7.8 & 8.5 & 8.4 & 4.7 \\
\hline Total & 37.4 & 43.8 & 44.8 & 48.6 & 32.0 \\
\hline
\end{tabular}
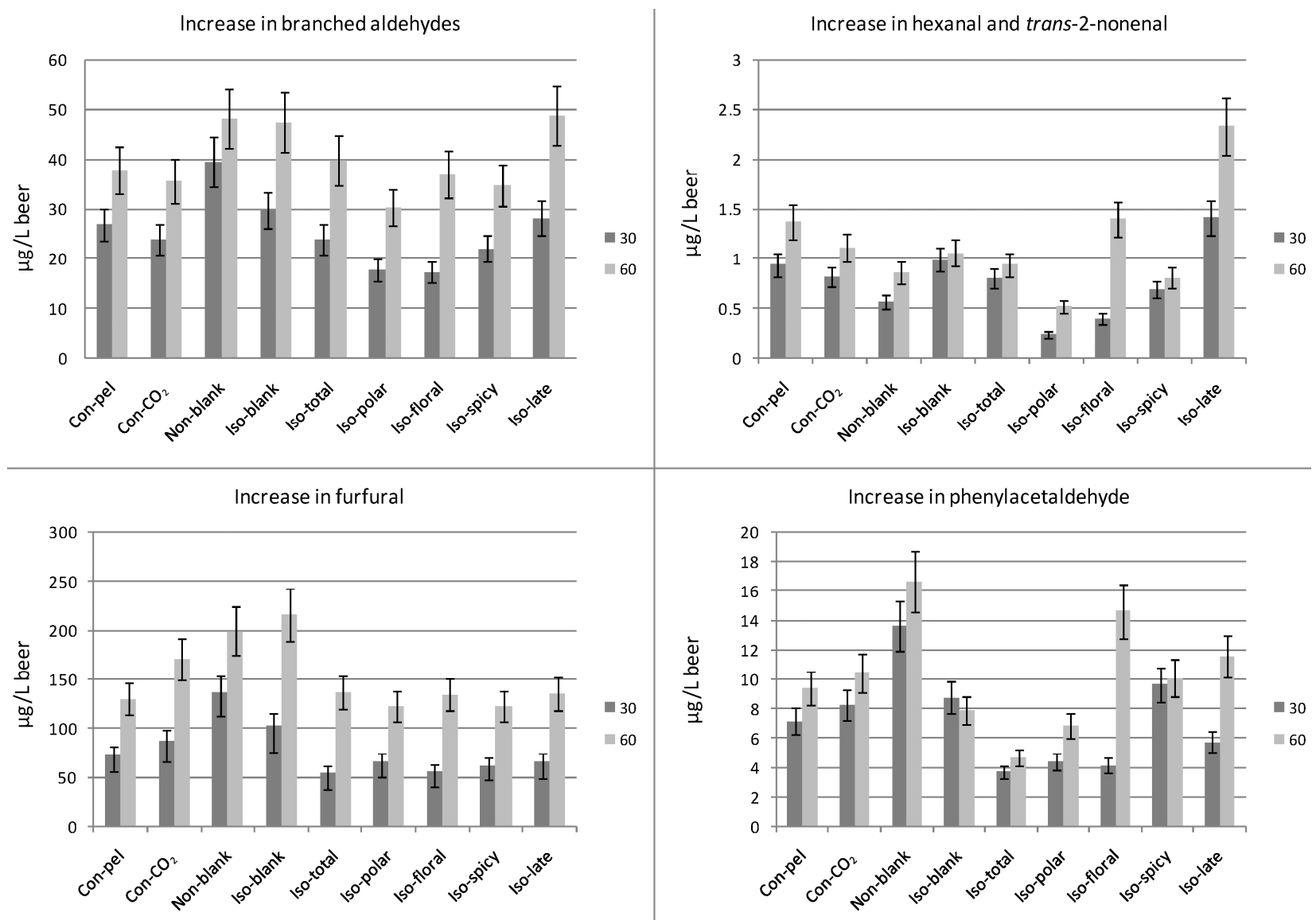

Fig. 7. Increase in levels of marker aldehydes in the pilot beers upon forced ageing ( 30 and 60 days at $30^{\circ} \mathrm{C}$, respectively) (mean of 5 determinations, $95 \%$ confidence intervals).

acids were measured as a function of forced ageing, in order to evaluate the overall flavour stability of the pilot beers.

Aldehydes were quantitatively determined by an extraction and detection methodology according to Vesely et al. ${ }^{38}$ The results for the fresh conventionally hopped beers and the iso-bittered or non-bittered reference beers are presented in Table IV. A relatively low content in aldehyde markers, ranging from 32.0 to $48.4 \mu \mathrm{g} / \mathrm{L}$ beer, was observed for these four fresh pilot beers. The total concentration was in the range of levels found in a recent study on flavour instability of commercial pale lager beers $^{28}$. When comparing the sum of marker aldehydes of the beers in Table IV, it was further noticed that the conventionally hopped fresh beers Con-pel and $\mathrm{Con}-\mathrm{CO}_{2}$ contained somewhat lower levels than the fresh reference beers 'Iso-blank' and 'Non-blank'. Levels of staling aldehyde markers in the fresh aromatised iso-bittered beers are shown in Table V. Also in these fresh beers a relatively low content in aldehydes was noticed, in particular in the late hopped iso-beer.

For interpretation of the data obtained from aldehyde measurement upon beer ageing, the components can be grouped into (1) branched aldehydes (2-methylpropanal, 2-methylbutanal, 3-methylbutanal), (2) hexanal and trans2-nonenal, (3) furfural, and (4) phenylacetaldehyde (Fig. 7). When comparing the four iso-bittered beers aromatised with the respective hop oils with their corresponding reference beer 'Iso-blank' or with the corresponding conventional late hopped beer (Iso-late), the increase in 
Table VI. Relative concentrations of total iso- $\alpha$-acids (\%) and T/C ratio $(\%)$ in fresh and forced aged beer samples of conventionally bittered and aromatised advanced bittered pilot beers.

\begin{tabular}{llcll}
\hline & & Fresh $^{\mathbf{a}}$ & $\mathbf{3 0 ~ d}^{\mathbf{b}}$ & $\mathbf{6 0 ~ d}^{\mathbf{c}}$ \\
\hline Con-pel & Rel. Bit. & & \\
& T/C-ratio & 100.0 & 93.7 & 88.4 \\
Con-CO 2 & 46 & 39 & 33 \\
& Rel. Bit. & 100.0 & 92.8 & 85.5 \\
Iso-blank & T/C-ratio & 53 & 40 & 33 \\
& Rel. Bit. & 100.0 & 94.2 & 93.4 \\
Iso-total & T/C-ratio & 30 & 26 & 22 \\
& Rel. Bit. & 100.0 & 95.7 & 91.6 \\
Iso-polar & T/C-ratio & 31 & 27 & 23 \\
& Rel. Bit. & 100.0 & 94.6 & 90.1 \\
Iso-floral & T/C-ratio & 30 & 26 & 23 \\
& Rel. Bit. & 100.0 & 98.3 & 91.5 \\
Iso-spicy & T/C-ratio & 30 & 27 & 23 \\
& Rel. Bit. & 100.0 & 95.2 & 90.7 \\
Iso-dry & T/C-ratio & 30 & 26 & 23 \\
& Rel. Bit. & 100.0 & 95.5 & 92.4 \\
Iso-late & T/C-ratio & 30 & 27 & 23 \\
& Rel. Bit. & 100.0 & 94.9 & 89.8 \\
& T/C-ratio & 33 & 29 & 24 \\
\hline
\end{tabular}

a Fresh beer sample.

${ }^{\mathrm{b}}$ Beer sample aged for 30 days at $30^{\circ} \mathrm{C}$.

${ }^{c}$ Beer sample aged for 60 days at $30^{\circ} \mathrm{C}$.

${ }^{\mathrm{d}}$ Bitterness relative to the initial concentration in the fresh beer (equalised to $100 \%)$

e The ratio (in percentage) of the sum of the concentrations of transisocohumulone and trans-isohumulone, to the sum of the concentrations of $c i s$-isocohumulone and $c i s$-isohumulone.

branched aldehydes upon ageing was always significantly lower. In general, the data obtained on the other staling aldehydes, i.e., the fatty acid oxidation aldehydes (hexanal, trans-2-nonenal), furfural, and phenylacetaldehyde, point to the same observation, except for the floral hop essence. Thus, in the case of application of total hop oil, polar essence or spicy essence, the increase in the staling aldehydes upon beer ageing was generally lower compared to both the reference beer 'Iso-blank' and the conventionally late-hopped beer 'Iso-late'.

Whether this points to some flavour stabilisation mechanism by the hop oils requires further investigation. In any case, based on analytical data on staling aldehydes as a function of beer ageing, application of the in-house hop oil preparations (total hop oil, polar essence, spicy essence) can be evaluated positively in terms of beer flavour stability.

Bittering principles as analytical markers for flavour deterioration. Bitterness profiles of fresh and aged pilot beers (30 days and 60 days at $30^{\circ} \mathrm{C}$, respectively) were determined by HPLC (for experimental details, see 'Materials and Methods'). Table VI shows the relative concentrations of total iso- $\alpha$-acids $(\%)$ and $\mathrm{T} / \mathrm{C}$-ratios in the fresh and aged beers. A higher stability of the bittering principles was clearly observed for the advanced hopped beers when compared to the conventionally hopped beers, in particular after 60 days of ageing. Indeed, after that ageing period, the bitterness concentration of all beers derived from the iso-bittered basic brew was at least $90 \%$ of the initial concentration in the corresponding fresh beers, regardless of the hop aromatisation method. Of all the pilot beers, the conventionally bittered beer prepared with non-isomerised hop extract $\left(\mathrm{Con}-\mathrm{CO}_{2}\right)$ showed the lowest stability of bittering principles. Results obtained in this study on the degradation of iso- $\alpha$-acids as a function
Table VII. Sensory ageing scores (0: completely fresh to 8: very strongly aged, undrinkable) for the conventionally bittered and aromatised advanced bittered beers.

\begin{tabular}{lccc}
\hline & \multicolumn{3}{c}{ Sensory ageing scores } \\
\cline { 2 - 4 } & Fresh & 30 days & 60 days \\
\hline Con-pel & 0.0 & 2.6 & 3.7 \\
Con-CO & 0.0 & 2.9 & 3.8 \\
Iso-blank & 0.9 & 3.2 & 4.9 \\
Iso-total & 0.0 & 2.9 & 4.2 \\
Iso-polar & 0.0 & 2.1 & 3.2 \\
Iso-floral & 0.0 & 2.5 & 4.0 \\
Iso-spicy & 0.0 & 2.7 & 3.8 \\
Iso-dry & 0.0 & 2.2 & 3.9 \\
Iso-late & 0.0 & 1.7 & 2.7 \\
\hline
\end{tabular}

of beer ageing and hopping technology are in full accordance with our previously published work ${ }^{18,19}$.

Sensory evaluation of beer ageing. Sensory ageing scores on a scale from 0 (completely fresh, no staling) to 8 (very strongly aged, undrinkable) were given to the beers by the trained taste panel of our institute (for details on procedure, see 'Material and Methods'). Fresh beers were judged to be completely fresh, except for the nonaromatised iso-bittered beer which gave a very weakly perceptible stale impression (see Table VII). This reference iso-bittered beer was also given the highest overallageing-score (4.9) after 60 days of storage at $30^{\circ} \mathrm{C}$, which corresponds with its relatively high initial amount of staling marker aldehydes and their relative strong increase upon ageing of this beer (also see Fig. 7). When aromatising this reference iso-bittered brew, either in the advanced way using our in-house hop oil preparations or using conventional late-hopping, lower sensory ageing scores were always observed. In, particular conventional late-hopping and the use of the polar hop essence markedly lowered the sensory ageing score of the iso-bittered beer.

Although the late hopped beer was certainly not the most stable beer based on profiling staling aldehydes (Fig. 7), it proved to be the beer with the lowest sensory ageing score. This finding points to the potential of hop aromatisation to mask aged staling flavours. Indeed, as mentioned earlier, the conventionally late-hopped brew scored high for hoppy aroma in the fresh beer (see Table III) and also contained the highest linalool level, far above the flavour threshold value (Fig. 2). In addition, our results confirmed the findings of Kaltner et al. ${ }^{23}$, who reported on better sensory ratings for forced-aged Pilsner beers when applying late hopping (either via addition of hop pellets at the end of the boil or in the whirlpool) and on the apparently contradictory information obtained by analytical data on staling compounds. In particular, the sensory intensity of hoppy aroma seems to be most relevant in respect to masking oxidised stale flavours, as the advanced aromatised beer 'Iso-polar' showed a high hoppy aroma intensity in the fresh beer (Table III), a relatively low sensory ageing score on storage (Table VII), with almost no presence of linalool (Fig. 2).

In general, it is clear from the sensory evaluations in Table VII that all beers aromatised with our in-house hop oil preparations showed lower ageing scores than the isobittered blank beer. Thus, by adding adequate amounts of these highly refined hop oil preparations, perception of sensory ageing of beer and of typical staling flavours can 
be suppressed by the clear and distinct hoppy flavours introduced into the beer.

\section{CONCLUSIONS}

In this study, analytical and sensory aspects of the hoppy character of conventionally and advanced hopped Pilsner-type beers were evaluated.

The level of analytical markers for hoppy aroma (i.e., linalool and sesquiterpenoids) depends on the selected hopping technology and on the nature of the hop oil fraction in the case with advanced hopping. Conventional aromatisation (i.e., late-hopping and dry-hopping of advanced bittered beers) resulted in high linalool and sesquiterpenoid levels in the fresh beers. Advanced aromatising by hop essences mainly had a pronounced effect on the sesquiterpenoid level.

A high hoppy aroma intensity was not always reflected by a high level of linalool. The use of linalool as an analytical marker for the estimation of hoppy aroma is only reliable when conventional aromatisation is applied. In addition, it was found that linalool as well as other hop oil constituents were introduced into the beer when using an iso- $\alpha$-acids extract for bittering purposes.

All hop oil preparations used in beer aromatisation imparted pronounced and pleasant hoppy flavour attributes. Moreover, the sensory impact of advanced hop aromatisation was not limited to beer aroma, but also affected bitterness perception and mouthfeel.

Upon beer ageing, the linalool content did not decrease, whereas the sesquiterpenoid level decreased in all beers. Analytical data on staling aldehydes and bittering principles upon ageing suggest that hop oil preparations may positively influence the flavour stability of the resulting beers. In particular, hop aromatisation clearly masks the sensory perception of staling flavours.

\section{ACKNOWLEDGEMENTS}

HVG - Hopfenverwertungsgenosschenschaft e.G. (Wolnzach, Germany) is thanked for providing hop products and for financial support of this study.

\section{REFERENCES}

1. Benitez, J. L., Forster, A., De Keukeleire, D., Moir, M., Sharpe, F. R., Verhagen L. C. and Westwood, K. T., Hops and Hop products - EBC Manual of Good Practice, Fachverlag Hans Carl: Nürnberg, Germany, 1997.

2. Biendl, M., Kollmannsberger, H. and Nitz, S., Occurrence of glycosidically bound flavor compounds in different hop products. Proceedings of the European Brewery Convention Congress, Dublin, 2003. Fachverlag Hans Carl: Nürnberg, Germany, CD ROM 2003, Contribution 21.

3. Daenen, L., Saison, D., De Cooman, L., Derdelinckx, G., Verachtert, H. and Delvaux, F., Flavour enhancement in beer: Hydrolysis of hop glycosides by yeast $\beta$-glucosidase. Cerevisia, 2007, 32(1), 24-36.

4. De Cooman, L., Aerts, G. and Overmeire, H., Alterations of the profiles of iso- $\alpha$-acids during beer ageing, marked instability of trans-iso- $\alpha$-acids and implications for beer bitterness consistency in relation to tetrahydroiso- $\alpha$-acids. J. Inst. Brew., 2000, 106(3), 169-178.

5. De Cooman, L., Aerts, G., Van Opstaele, F., Goiris, K., Syryn, E., De Rouck, G., De Ridder, M. and De Keukeleire, D., New trends in advanced hopping - Part 2: application of varietal hop aromas. Cerevisia, 2004, 29(1), 81-87.
6. De Cooman, L., Aerts, G., Witters, A., De Ridder, M., Boeykens, A., Goiris, K. and De Keukeleire, D., Comparative study of the stability of iso- $\alpha$-acids, dihydroiso- $\alpha$-acids and tetrahydroiso- $\alpha$-acids during beer ageing. Proceedings of the European Brewery Convention Congress, Budapest, 2001. Fachverlag Hans Carl: Nürnberg, Germany, CD ROM 2001, Contribution 60 .

7. De Rouck, G., Flores-Gonzáles, A. G., De Clippeleer, J., De Cock, J., De Cooman, L. and Aerts, G., Sufficient formation and removal of dimethyl sulfide (DMS) without classic wort boiling. Brewing Science-Monatsschr. Brauwiss., 2010, 63, 31-40.

8. Eyres, G. T., Marriott, P. J. and Dufour, J. P., Comparison of odor-active compounds in the spicy fraction of hops (Humulus lupulus L.) essential oil from four different varieties. J. Agric. Food Chem., 2007, 55(15), 6252-6261.

9. Fritsch, H. T. and Schieberle, P., Identification based on quantitative measurements and aroma recombination of the character impact odorants in a Bavarian Pilsner-type beer. J. Agric. Food Chem., 2005, 53, 7544-7551.

10. Fukuoka, Y. and Kowaka, M., Identification of compounds imparting hoppy flavor to beer. Brewers Digest, 1985, 46-48.

11. Goiris, K., De Ridder, M., De Rouck, G., Boeykens, A., Van Opstaele, F., Aerts, G., De Cooman, L. and De Keukeleire, D., The oxygenated sesquiterpenoid fraction of hops in relation to the spicy hop character of beer. J. Inst. Brew., 2002, 108(1), 8693.

12. Goiris, K., Syryn, E., Jaskula, B., Van Opstaele, F., De Rouck, G., Aerts, G. and De Cooman, L., Hop polyphenols: potential for beer flavour and flavour stability. Proceedings of the European Brewery Convention Congress, Prague, 2005. Fachverlag Hans Carl: Nürnberg, Germany, CD ROM 2005, Contribution 87.

13. Goldstein, H., Ting, P., Navarro, A. and Ryder, D., Water-soluble hop flavor precursors and their role in beer flavor. Proceedings of the European Brewery Convention Congress, Cannes, 1999. Fachverlag Hans Carl: Nürnberg, Germany, Contribution 9.

14. Hanke, S., Herrmann, M., Rückerl, J., Schönberger, C. and Back, W., Hop volatile compounds (Part II): transfer rates of hop compounds from hop pellets to wort and beer. Brewing Science-Monatsschr. Brauwiss., 2008, 61(7/8), 140-147.

15. Hughes, P., Flavour, froth, and finesse - the legacy of hops to beer (a review). Eur. Brew. Conv. Congr., Hamburg, 2009. Lecture 25 .

16. Irwin, A. J., Varietal dependence of hop flavour volatiles in lager. J. Inst. Brew., 1989, 95, 185-194.

17. Jaskula, B., Goiris, K., De Rouck, G., Aerts, G. and De Cooman, L., Enhanced quantitative extraction and HPLC determination of hop and beer bitter acids. J. Inst. Brew., 2007, 113(4), 381-390.

18. Jaskula, B., Goiris, K., Van Opstaele, F., De Rouck, G., Aerts, G. and De Cooman, L., Hopping technology in relation to $\alpha$-acids isomerization yield, final utilization, and stability of beer bitterness. J. Am. Soc. Brew. Chem., 2009, 67(1), 44-57.

19. Jaskula, B., Syryn, E., Goiris, K., De Rouck, G., Van Opstaele, F., De Clippeleer, J., Aerts, G. and De Cooman, L., Hopping technology in relation to beer bitterness consistency and flavour stability. J. Am. Soc. Brew. Chem., 2007, 65(1), 38-46.

20. Kaltner, D. and Mitter, W., Changes in hop derived compounds during beer production and aging. In: Hop Flavor and aroma Proceedings of the 1st International Brewers Symposium, Shellhammer, T. H. (ed.), Master Brewers Association of the Americas: St. Paul, Minnesota, 2009, pp. 37-47.

21. Kaltner, D., Steinhaus, M., Mitter, W., Biendl, M. and Schieberle, P., (R)-Linalool als Schlüsselaromastoff für das Hopfenaroma in Bier und sein Verhalten während der Bieralterung. Monatsschr. Brauwiss., 2003, 56, 192-196.

22. Kaltner, D., Thum, B., Forster, C. and Back, W., Untersuchungen zum Hopfenaroma in Pilsner Bieren bei Variation technologischer Parameter. Monatsschr. Brauwiss., 2001, 54, 199-205. 
23. Kaltner, D., Thum, B., Forster, C. and Back, W., Hops - Investigations into technological and flavor effects in beer. Brauwelt International, 2001, 19, 40-45.

24. Kishimoto, T., Wanikawa, A., Kagami, N. and Kawatsura, K., Analysis of hop-derived terpenoids in beer and evaluation of their behavior using the stir bar-sorptive extraction method with GC-MS. J. Agric. Food Chem., 2005, 53, 4701-4707.

25. Kollmannsberger, H., Biendl, M. and Nitz, S., Occurrence of glycosidically bound flavour compounds in hops, hop products and beer. Monatsschr. Brauwiss., 2006, 5/6, 83-89.

26. Krofta, K., Mikyška, A. and Hašková, D., Antioxidant characteristics of hops and hop products. J. Inst. Brew., 2008, 114(2), 160-166.

27. Lermusieau, G., Bulens, M. and Collin, S., Use of GC-olfactometry to identify the hop aromatic compounds in beer. $J$. Agric. Food Chem., 2001, 49, 3867-3874.

28. Malfliet, S., Van Opstaele, F., De Clippeleer, J., Syryn, E., Goiris, K., De Cooman, L. and Aerts, G., Flavour instability of pale lager beers: determination of analytical markers in relation to sensory ageing. J. Inst. Brew., 2008, 114(2), 180-192.

29. Marriott, R., Flavor and aroma characteristics of pure hop aroma in different beer styles. In: Hop Flavor and Aroma - Proceedings of the 1st International Brewers Symposium, Shellhammer, T. H. (ed.), Master Brewers Association of the Americas: St. Paul, Minnesota, 2009, pp. 79-89.

30. Mitter, W., Biendl, M. and Kaltner, D., Behaviour of hop derived aroma substances during wort boiling. Monograph 31 of the European Brewery Convention Symposium 'Flavour and Flavour Stability', Nancy, 2001, Fachverlag Hans Carl: Nürnberg, Germany, CD ROM 2001, Contribution 11.

31. Nickerson, G. B. and Van Engel, L., Hop aroma component profile and the aroma unit. J. Am. Soc. Brew. Chem., 1992, 50(3), 77-81.

32. Peacock, V. E. and Deinzer, M. L., Fate of hop oil components in beer. J. Am. Soc. Brew. Chem., 1988, 46, 104-107.
33. Peacock, V. E. and Deinzer, M. L., Chemistry of hop aroma in beer. J. Am. Soc. Brew. Chem., 1981, 136-141.

34. Schönberger, Ch., Korn, S. and Marriott, R., Evaluations of pure hop aromas in alcohol free beer. Brauwelt International, 2005 , 23, 181-184.

35. Steinhaus, M., Fritsch, H. T. and Schieberle, P., Quantitation of $(R)$ - and (S)-linalool in beer using solid phase microextraction (SPME) in combination with a stable isotope dilution assay (SIDA). J. Agric. Food Chem., 2003, 51, 7100-7105.

36. Van Hoyweghen, L., Biendl, M. and Heyerick, A., Radical scavenging capacity of hop-derived products. Brewing ScienceMonatsschr. Brauwiss., 2010, 63, 1-5.

37. Van Opstaele, F., Goiris, K., Syryn, E., De Cooman, L. and Aerts, G., Novel hop-derived ingredients and drinkability. Monograph 34 of the European Brewery Convention Symposium 'Drinkability', Edinburgh, 2006. Fachverlag Hans Carl: Nürnberg, Germany, CD ROM 2006, Contribution 12.

38. Vesely, P., Lusk, L., Basarova, G., Seabrooks, J. and Ryder, D., Analysis of aldehydes in beer using solid-phase microextraction with on-fiber derivatization and gas chromatography/mass spectrometry. J. Agric. Food Chem., 2003, 51(24), 6941-6944.

39. Yamaguchi, N., Satoh-Yamaguchi, K. and Ono, M., In vitro evaluation of antibacterial, anticollagenase, and antioxidant activities of hop components (Humulus lupulus) addressing acne vulgaris. Phytomedicine, 2009, 16, 369-376.

40. Yang, X., Lederer, C., McDaniel, M. and Deinzer, M., Hydrolysis products of caryophyllene oxide in hops and beer. J. Agric. Food Chem., 1993, 41, 2082-2085.

41. Zufall, C., Wackerbauer, K. and Brandt, C., The influence of hop products on beer flavour stability. Brewing ScienceMonatsschr. Brauwiss., 2008, 11/12, 113-120.

(Manuscript accepted for publication November 2010) 